\title{
Interleukin 29 activates expression of tissue inhibitor of metalloproteinase 1 in macrophages via toll-like receptor 2
}

\author{
HAOQIANG ZHANG ${ }^{1}$, BING SONG ${ }^{1}$ and SHAOHENG HE ${ }^{2}$
}

\author{
Departments of ${ }^{1}$ Endocrinology and ${ }^{2}$ Ear Nose and Throat, Allergy and Clinical Immunology Research Center, \\ The First Affiliated Hospital of Jinzhou Medical University, Jinzhou, Liaoning 121001, P.R. China
}

Received July 7, 2017; Accepted November 28, 2017

DOI: $10.3892 / \mathrm{mmr} .2018 .8865$

\begin{abstract}
Obesity and diabetes are characterized by low grade chronic inflammation status and insulin resistance in adipose tissue associated with metalloproteinase inhibitor 1 (TIMP1). Interleukin (IL)29, exhibits multiple immune regulatory activities. However, the role of IL29 and its effects on TIMP1 remain to be elucidated. The present study was designed to investigate the effects of IL29 on expression of TIMP1 in macrophages associated with inflammation in adipose tissue. IL29 and high glucose were used to activate Raw264.7 cells and primary macrophages with or without antibody-mediated inhibition of toll like receptor (TLR) 2 and TLR4. TIMP1 was measured in culture media of Raw 264.7 cells and primary macrophages by ELISA. IL29 and high glucose increased TIMP1 levels in Raw264.7 cells and primary macrophages. Antibody-mediated inhibition of TLR2 or TLR2 gene knockout decreased TIMP1 levels activated by IL29, however not by high glucose in the medium of Raw264.7 cells and primary macrophages. Furthermore, antibody-mediated inhibition of TLR4 or TLR4 gene knockout decreased TIMP1 levels which were stimulated by high glucose, not by IL29 in the medium of Raw 264.7 cells and primary macrophages. The results of the present study indicate that TLR2 is involved in IL29-stimulated TIMP1 expression in Raw264.7 cells and primary macrophages.
\end{abstract}

Correspondence to: Dr Bing Song, Department of Endocrinology, The First Affiliated Hospital of Jinzhou Medical University, 5-2 Renmin Road, Jinzhou, Liaoning 121001, P.R. China

E-mail: 1131780275@qq.com

Professor Shaoheng He, Department of Ear Nose and Throat, Allergy and Clinical Immunology Research Center, The First Affiliated Hospital of Jinzhou Medical University, 5-2 Renmin Road, Jinzhou, Liaoning 121001, P.R. China

E-mail: 13634965277@163.com

Key words: interleukin 29, toll like receptor 2, toll like receptor 4, tissue metalloproteinase inhibitor 1 , macrophage

\section{Introduction}

The prevalence of obesity, prediabetes and diabetes has increased in the last three decades (1-5). Diabetes and obesity are characterized by low grade chronic inflammation status and insulin resistance in adipose tissue (6). Several researchers identified infiltration of macrophages in adipose tissue of diabetic or obese individuals by immunohistochemistry, polymerase chain reaction (PCR) or flow cytometry with F4/80 or CD68 antibodies (7-9).

Interleukin (IL)29 exhibits multiple immune regulatory activities, including antiviral, antiproliferation and antitumor properties. Previous studies have suggested that IL29 is involved in the regulation of Th (T helper) $1 / \mathrm{Th} 2$ responses and function of B cells, plasmacytoma dendritic cells and macrophages (10-14). IL29 enhanced lipopolysaccharide (LPS)-induced inflammatory cytokine production from toll like receptor 4 signaling pathway in RAW264.7 cells (15).

Tissue inhibitor of metalloproteinase (TIMP)-associated disorders have been implicated in pathophysiological processes of obesity and diabetes in humans. Concentrations of matrix metalloproteinases (MMPs) and TIMPs are increased in the plasma of diabetic and obese humans (16). A previous study demonstrated that high glucose and interferon- $\gamma$ increased MMP1 expression in U937 mononuclear cells (17). However, the TIMP1 expression pattern following stimulation with IL29 in Raw264.7 cells and primary macrophages remains to be elucidated. Therefore, the present study investigated the effects of IL29 and high glucose on TIMP1 in Raw264.7 cells and primary macrophages. The results of the present study may aid in elucidating the underlying mechanisms of obesity and diabetes mellitus.

\section{Materials and methods}

Human study. Adipose tissues were collected from patients with obesity (8 males, 40-50 years old, BMI>28) and age and sex matched lean controls (8 males, 40-50 years old, BMI $<24)$ during abdominal surgery from the First Affiliated Hospital of Jinzhou Medical University (Jinzhou, China) from December 2016 to January 2017. All volunteers signed written informed consent forms prior to the study. All experiments were approved by the Medical Ethics Committee of the First Affiliated Hospital of Jinzhou Medical University. 
Raw264.7 cell culture. Raw264.7 cells were purchased from American Type Culture Collection (Manassas, VA, USA) and cultured in glucose free 1640 medium (Thermo Fisher Scientific, Inc., Waltham. MA, USA) with $5 \mathrm{mM}$ glucose, supplemented with $10 \%$ fetal bovine serum (FBS; Tiangen Biotech Co., Ltd., Beijing, China) and $1 \%$ penicillin-streptomycin $(\mathrm{P} / \mathrm{S})$. The medium was replaced at least once every two days. Cells were harvested for passaging when plates were $90 \%$ confluent.

Primarymacrophage extractionand culture. TLR $2^{--}$or TLR $4^{-1-}$ mice backcrossed on C57BL/6J from the Jackson Laboratory (Ben Harbor, ME, USA or Sacramento, CA, USA) were housed with C57BL/6J mice from Beijing HFK Bioscience Co., Ltd. (Beijing, China) to get TLR2 or $4^{+/+}$and TLR2 or $4^{-/}$sex and age matched littermate mice used for studies in vitro. A total number of 315 mice were used. Primary macrophages were extracted from abdominal cavities of TLR2 $2^{+/+}$or TLR $4^{+/+}$and TLR2 ${ }^{-/}$or TLR $4^{-/}$mice. Briefly, $10 \mathrm{ml}$ bacteria free PBS was injected to the abdominal cavities multiple times in each fresh sacrificed mouse in order to generate macrophages, and then was pumped out following massaging for $5 \mathrm{~min}$. Cells in the PBS extracted from abdominal cavities were centrifuged at $700 \mathrm{x} \mathrm{g}$ for $5 \mathrm{~min}$ at $20-25^{\circ} \mathrm{C}$ and cultured in the aforementioned 1640 medium. The medium was replaced following $12 \mathrm{~h}$ of culture to remove unadherent cells from macrophages. All animal studies were approved by the Ethics Committee for Experimental Research, Jinzhou Medical University (Jinzhou, China).

IL29 and high glucose-activation assays, and antibody-mediated inhibition assays. Cells (Raw264.7 cells and primary macrophages) were cultured in the 1640 medium as previously described with $5 \mathrm{mM}$ glucose, $10 \%$ FBS and $1 \% \mathrm{P} / \mathrm{S}$ for two days, and then cultured in FBS free medium for IL29 and high glucose-activated assays. Activation was performed by treatment with IL29 at a concentration of 0, 10,30 or $100 \mathrm{ng} / \mathrm{ml}$ or $25 \mathrm{mM}$ glucose for $24 \mathrm{~h}$ (low dose group $=5 \mathrm{mM}$ and high dose group $=30 \mathrm{mM}$ ). Antibodies against TLR2 or 4 (dilution, 1:100; cat no. 10472R; Beijing Biosynthesis Biotechnology Co., Ltd., Beijing, China) were added to the medium at $37^{\circ} \mathrm{C}$ for $24 \mathrm{~h}$ to inhibit TLR2 or TLR4. Subsequently, cells were harvested with a cell scraper followed by centrifugation at $700 \mathrm{x} \mathrm{g}$ for $5 \mathrm{~min}$ at $20-25^{\circ} \mathrm{C}$ for further research.

Western blotting. Western blotting was performed according to a previously described protocol (18). Total proteins from adipose tissue were extracted using radioimmunoprecipitation assay buffer (Beyotime Institute of Biotechnology, Haimen, China) (with $1 \%$ phenylmethane sulfonyl fluoride or phenylmethylsulfonyl fluoride). Subsequently, a bicinchoninic acid assay was performed to measure protein concentration in middle extracting solution. Proteins were separated by SDS-PAGE on $10 \%$ gels, transferred to polyvinylidene fluoride membranes and blocked with skimmed milk for $2 \mathrm{~h}$ at room temperature. Rabbit-anti-mouse (or human) primary antibodies to TIMP1 (1:500; cat no. wl02342; Wanleibo Co., Ltd., Shanghai, China), myeloid differentiation primary response protein MyD88 (MyD88; 1:300; cat no. bs-1047R;
Table I. Primers for IL6, TNF $\alpha$ and GAPDH.

\begin{tabular}{ll}
\hline Gene & \multicolumn{1}{c}{ Sequence (5'-3') } \\
\hline IL6 & \\
Forward & ATGAAGTTCCTCTCTGCAAGAGACT \\
Reverse & CACTAGGTTTGCCGAGTAGATCTC \\
TNF $\alpha$ & \\
Forward & TGTCTCAGCCTCTTCTCATT \\
Reverse & AGATGATCTGAGTGTGAGGG \\
GAPDH & \\
Forward & TTGTCAAGCTCATTTCCTGGTATG \\
Reverse & GGATAGGGCCTCTCTTGCTCA \\
\hline
\end{tabular}

IL, interleukin; TNF $\alpha$, tumor necrosis factor $\alpha$.

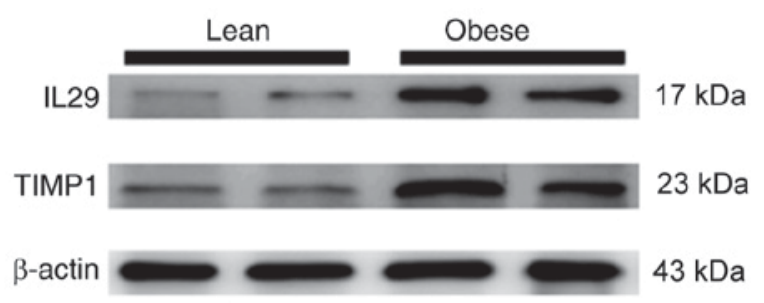

Figure 1. IL29 and TIMP1 expression in adipose tissue of human individuals. IL29 and TIMP1 expression levels were measured by western blot analysis. Elevated IL29 and TIMP1 expression levels were detected in human adipose tissue, compared with lean individuals. IL, interleukin; TIMP1, metalloproteinase inhibitor 1.

Beijing Biosynthesis Biotechnology Co., Ltd.), IL29 (1:1,500; cat no. ab38569; Abcam, Cambridge, MA, USA) and $\beta$-actin (1:3,000; cat no. AB21800; Absci, Vancouver, WA, USA) were used to bind target proteins at $4^{\circ} \mathrm{C}$ overnight. Following incubation with goat-anti-rabbit secondary antibody $(1: 5,000$; cat no. ABL3012-2; Absci, USA) for $2 \mathrm{~h}$ at $20-25^{\circ} \mathrm{C}$, an Enhanced Chemiluminescence kit (Wanleibo Co., Ltd.) was used to detect protein expression.

Immunofluorescence. Raw264.7 cells were collected by centrifugation $\left(700 \mathrm{x} \mathrm{g}\right.$ for $5 \mathrm{~min}$ at $20-25^{\circ} \mathrm{C}$ ) and seeded on dish climbing glasses (https://item.taobao.com/item. $\mathrm{htm}$ ?id=13540518880) in 24-well plate for $24 \mathrm{~h}$. IL29 and high glucose-activated assays were performed as described previously, for $24 \mathrm{~h}$. Raw 264.7 cells were rinsed 3 times with PBS and fixed with $4 \%$ paraformaldehyde for $30 \mathrm{~min}$ at $20-25^{\circ} \mathrm{C}$. Non-specific binding was blocked in PBS containing 5\% normal goat serum (cat no. SL03B; Beijing Solarbio Science \& Technology Co., Ltd., Beijing, China) at room temperature for $1 \mathrm{~h}$. Cells were initially incubated with primary antibodies [rabbit anti-mouse TLR2 (cat no. 10472R; $1: 300$ ) or TLR4 (cat no. 1021R; $1: 300$ ) at $4^{\circ} \mathrm{C}$ on a shaker overnight]. Subsequently, climbing glasses with Raw264.7 cells were washed 3 times in PBS at room temperature prior to incubation with goat anti-rabbit fluorescein isothiocyanate (green; Wanleibo Co., Ltd., Shanghai, China; 1:200; cat no. WLA031a) or Alexa Fluor 594 (red; Thermo Fisher Scientific, Inc,. 1:300; cat no. A-11032) secondary antibodies in the dark at room 
A

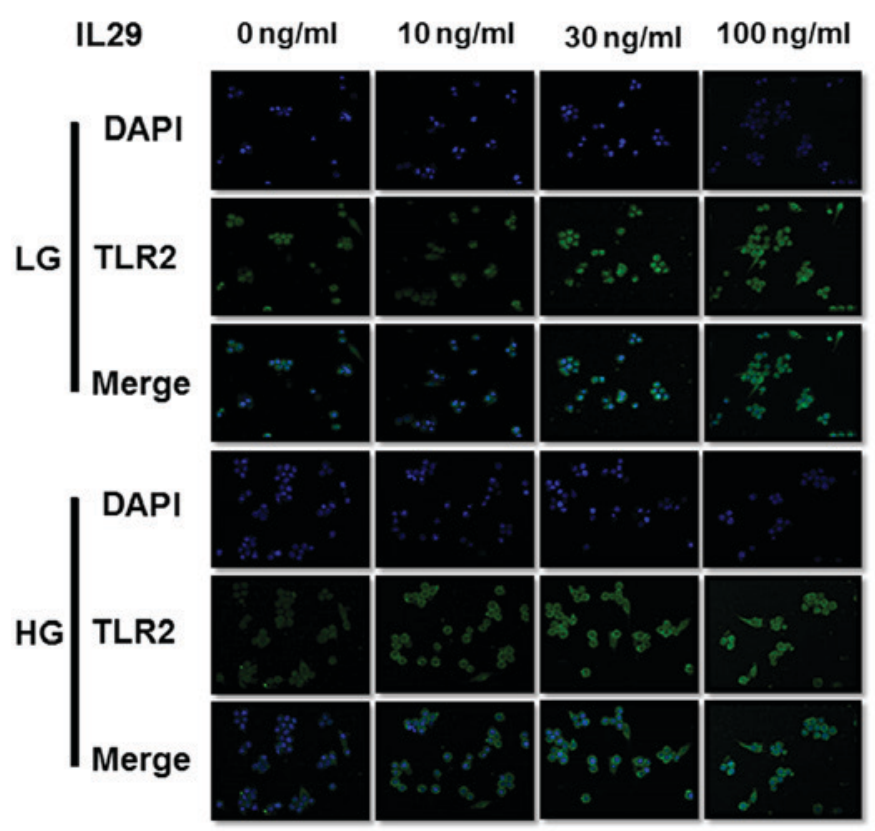

B

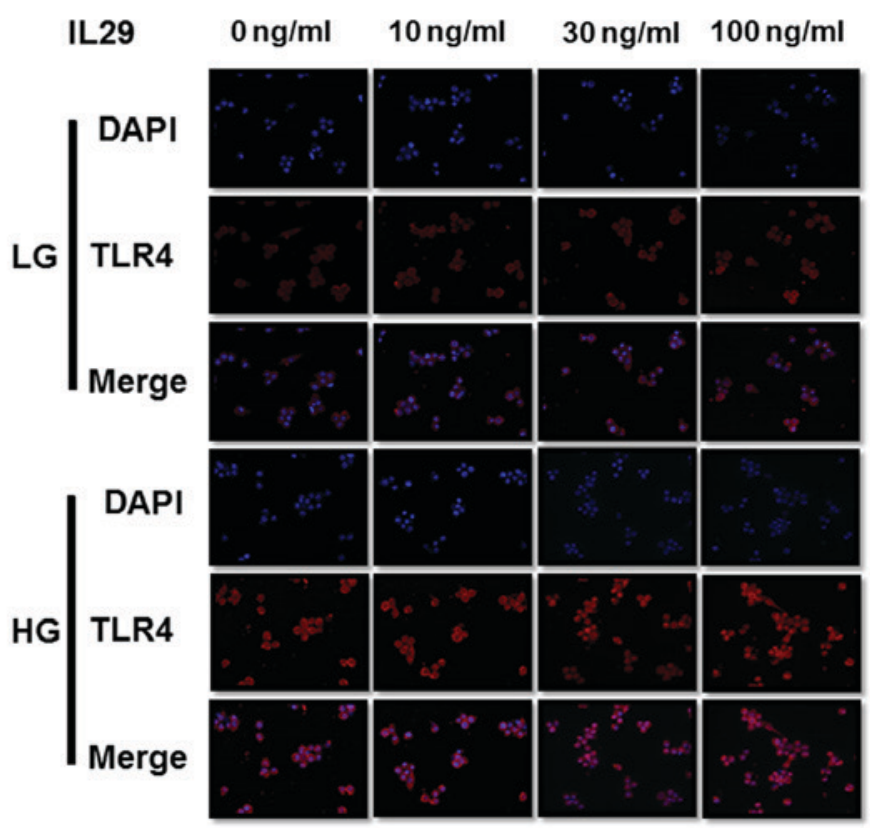

Figure 2. TLR2 and 4 expressions were stimulated by IL29 and high glucose in Raw264.7 cells, detected by immunofluorescence. (A) IL29 stimulated TLR2 expression in a concentration dependent manner, however did not affect TLR4 expression. (B) High glucose activated TLR4 expression in Raw264.7 cells. However, no elevated TLR2 level was detected following high glucose stimulation (x400). TLR, toll-like receptor; IL, interleukin; LG, low glucose; HG, high glucose.

temperature for $1 \mathrm{~h}$. Following washing with PBS 3 times, TLR2 and 4 expression levels were observed under a fluorescence microscope.

ELISA. TIMP1 in conditioned media was quantified using sandwich ELISA kits (cat no. MTM100) according to the manufacturers' protocol (R\&D Systems, Inc., Minneapolis, MN, USA).

Reverse transcription-quantitative $(R T-q) P C R$ assay. Total RNA was extracted from the Raw264.7 cell line using TRIzol ${ }^{\circledR}$ reagent (Thermo Fisher Scientific, Inc.) and dissolved in RNase free water with RNase inhibitor added. Prior to cDNA synthesis, RNA concentration was measured by Nanodrop 2000 (Thermo Fisher Scientific, Inc.) and modified to $100 \mu \mathrm{g} / \mu \mathrm{l}$ with diethyl pyrocarbonate (DEPC) water (Life Technologies; Thermo Fisher Scientific, Inc., cat no. AM9915G). All experiments were performed according to the manufacturers' protocol of PrimeScriptTM RT reagent kit with gDNA Eraser (Takara Bio, Inc., Otsu, Japan). DNA was removed in a $10 \mu \mathrm{l}$ reaction with RNA sample (1 $\mu \mathrm{l}), 5 \mathrm{X}$ gDNA Eraser Buffer $(2 \mu \mathrm{l})$, gDNA Eraser $(1 \mu \mathrm{l})$ and RNase Free $\mathrm{ddH}_{2} \mathrm{O}(6 \mu \mathrm{l})$ for $2 \mathrm{~min}$ at $42^{\circ} \mathrm{C}$. The cDNA was synthesized in a $20 \mu \mathrm{l}$ reaction with Primer Script RT Enzyme Mix (1 $\mu \mathrm{l})$, RT Primer Mix $(1 \mu \mathrm{l})$, 5X Primer Script Buffer (4 $\mu \mathrm{l})$, RNase Free $\mathrm{dH}_{2} \mathrm{O}(4 \mu \mathrm{l})$, and the $10 \mu \mathrm{l}$ reaction mixture from the previous step. The RT was performed in $20 \mu \mathrm{l}$ reactions at $25^{\circ} \mathrm{C}$ for $10 \mathrm{~min}$ followed by $37^{\circ} \mathrm{C}$ for $15 \mathrm{~min}$ and final denaturation at $85^{\circ} \mathrm{C}$ for $5 \mathrm{~min}$. The cDNA was stored at $-80^{\circ} \mathrm{C}$ until further use. The expression of IL- 6 mRNA and tumor necrosis factor- $\alpha$ (TNF- $\alpha$ ) mRNA was analyzed in $20 \mu \mathrm{l}$ reactions with $2 \mathrm{X}$ GreenStar Master Mix $(10 \mu \mathrm{l})$, forward primer $(1 \mu \mathrm{l}, 10 \mathrm{pmol} / \mu \mathrm{l})$, reverse primer
(1 $\mu \mathrm{l}, 10 \mathrm{pmol} / \mu \mathrm{l})$, DEPC water $(6 \mu \mathrm{l})$ and template DNA ( $2 \mu \mathrm{l})$ from reverse transcription. Primers were designed and synthesized by Sangon Biotech (Sangon Biotech Co., Ltd, Shanghai, China; Table I). qPCR experiments were performed according to the manufacturers' protocol of AccuPower ${ }^{\circledR} 2 \mathrm{X}$ GreenStar qPCR Master Mix kit with gDNA Eraser (Bioneer Corporation, Daejeon, Korea). Reactions were performed in $20 \mu \mathrm{l}$ volume and the following thermocycling conditions were used for PCR: Initial denaturation for $30 \mathrm{sec}$ at $95^{\circ} \mathrm{C} ; 45$ cycles of $95^{\circ} \mathrm{C}$ for $5 \mathrm{sec}$ and $60^{\circ} \mathrm{C}$ for $34 \mathrm{sec}$. Relative quantification of gene expression was performed using comparative $2^{-\Delta \Delta \mathrm{Cq}}$ method. GAPDH was used as a reference gene.

Statistical analysis. Data are presented as the mean \pm standard error of the mean, and analyzed by one-way analysis of variance between multiple groups, followed by the least significant difference post-hoc test. Interaction effects were analyzed by analysis of variance of factorial design. SPSS software (version 20.0; IBM SPSS, Armonk, NY, USA) was used for data analysis. $\mathrm{P}<0.05$ was considered to indicate a statistically significant difference.

\section{Results}

IL29 and TIMP1 levels are increased in adipose tissue of patients with obesity. In this study, elevated levels of IL29 and TIMP1 in adipose tissue of obese individuals compared with lean individuals was observed (Fig. 1).

IL29 and high glucose activate TIMP1 release in Raw264.7 cells. In the present study, IL29 and high glucose stimulated TLR2 and TLR4 expression respectively (Fig. 2A and B), 
A

\begin{tabular}{|c|c|c|c|c|c|c|c|c|}
\hline \multirow[b]{2}{*}{ IL29 (ng/m } & \multicolumn{4}{|c|}{ LG } & \multicolumn{4}{|c|}{ HG } \\
\hline & 0 & 10 & 30 & 100 & 0 & 10 & 30 & 100 \\
\hline
\end{tabular}

B
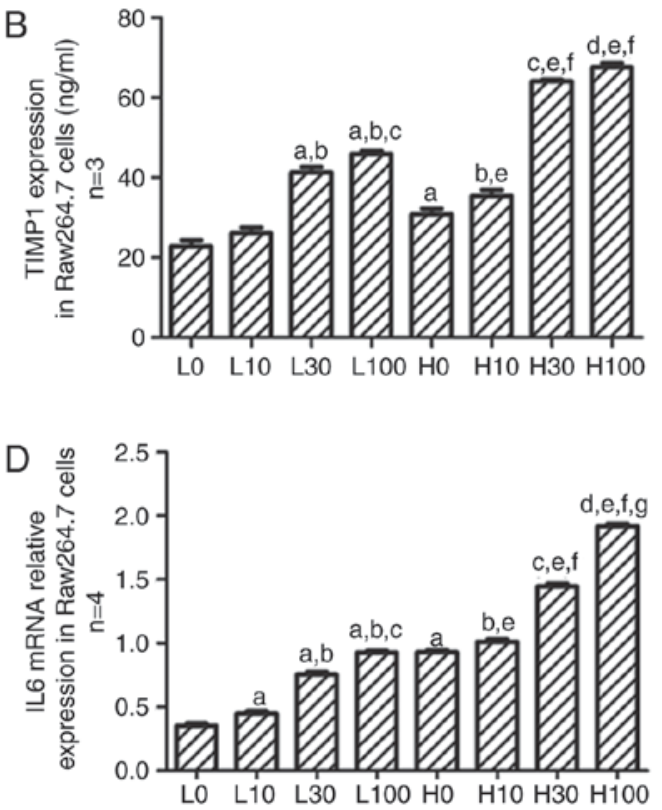
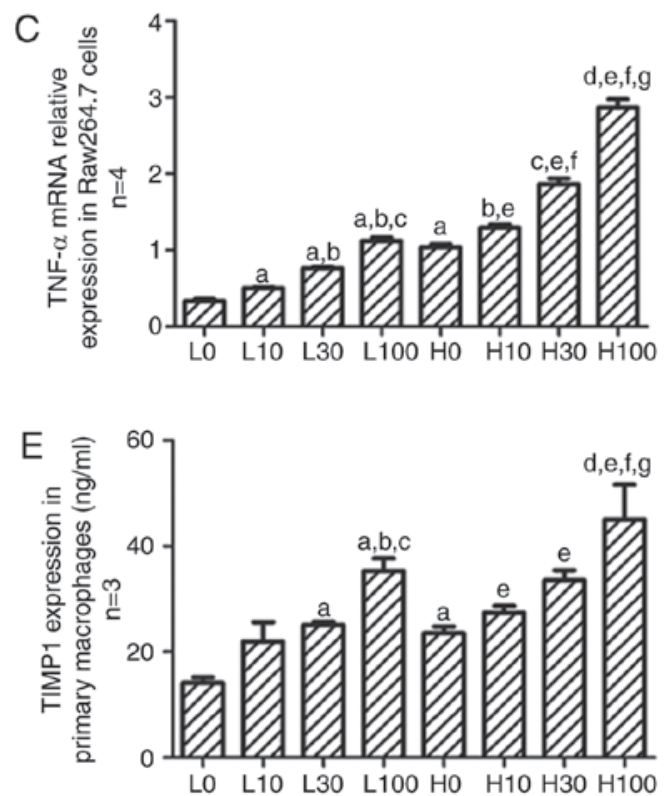

Figure 3. IL29 and high glucose stimulate TIMP1, MyD88, TNF- $\alpha$ and IL6 expression in Raw264.7 cells as well as TIMP1 levels in primary macrophages. (A) Western blotting detected elevated levels of MyD88 protein in Raw264.7 cells. (B) ELISA assay was performed to study the effects of IL29 and high glucose on TIMP1 expression in Raw264.7 cells. Expression of (C) TNF- $\alpha$ and (D) IL6 mRNA induced by IL29 and high glucose stimulation in Raw264.7 cells. (E) ELISA assay was performed to study the effects of IL29 and high glucose on TIMP1 expression in primary macrophages. ${ }^{\mathrm{a}} \mathrm{P}<0.05 \mathrm{vs}$. L0, ${ }^{\mathrm{b}} \mathrm{P}<0.05 \mathrm{vs}$. L10, ${ }^{\mathrm{c}} \mathrm{P}<0.05$ vs. L30, ${ }^{\mathrm{d}} \mathrm{P}<0.05$ vs. $\mathrm{L} 100,{ }^{\mathrm{e}} \mathrm{P}<0.05$ vs. $\mathrm{H} 0,{ }^{\mathrm{f}} \mathrm{P}<0.05$ vs. H10, ${ }^{\mathrm{g}} \mathrm{P}<0.05$ vs. H30. L0, low glucose and $0 \mathrm{ng} / \mathrm{ml} \mathrm{IL} 29$ group; L10, low glucose and $10 \mathrm{ng} / \mathrm{ml}$ IL29 group; L30, low glucose and $30 \mathrm{ng} / \mathrm{ml}$ IL29 group; L100, low glucose and $100 \mathrm{ng} / \mathrm{ml}$ IL29 group; H0, high glucose and 0 ng/ml IL29 group; H10, high glucose and $10 \mathrm{ng} / \mathrm{ml}$ IL29 group; H30, high glucose and $30 \mathrm{ng} / \mathrm{ml}$ IL29 group; H100, high glucose and $100 \mathrm{ng} / \mathrm{ml}$ IL29 group; IL, interleukin; TIMP1, metalloproteinase inhibitor 1; TNF- $\alpha$, tumor necrosis factor- $\alpha$; MyD8, myeloid differentiation primary response protein MyD88.

A

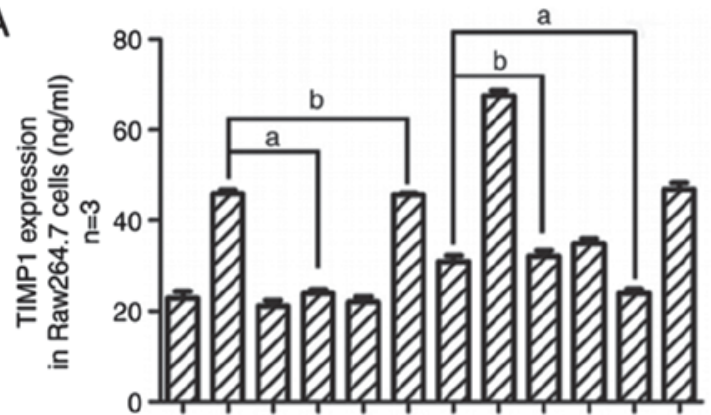

IL29 (ng/ml) $0 \begin{array}{llllllllllll}100 & 0 & 100 & 0 & 100 & 0 & 100 & 0 & 100 & 0 & 100\end{array}$ $\mathrm{HG}--_{-}-c_{+}+++$

TLR2 antibody --++----++-

TLR4 antibody ----++----++
B

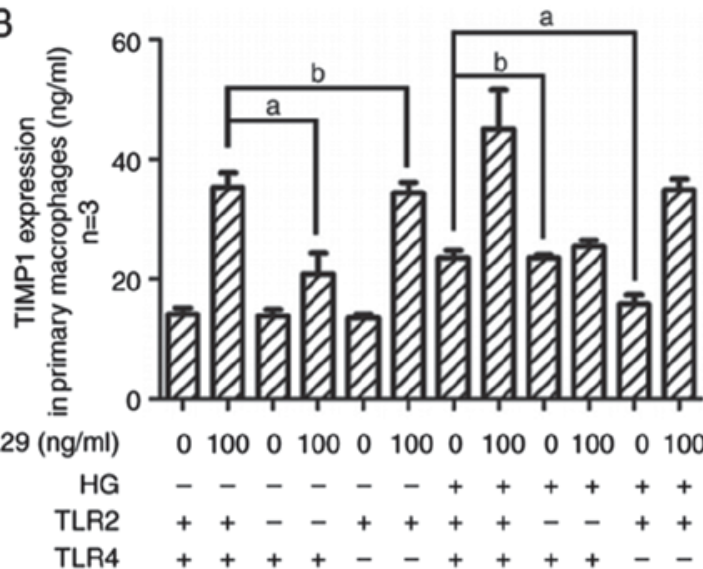

Figure 4. TIMP1 expression is decreased by antibody-mediated inhibition of TLR 2 and 4 , and TLR 2 and 4 gene knockout. ${ }^{\text {a }}<0.05$ demonstrated that antibody-mediated inhibition of TLR2 and 4 and gene knockout suppressed TIMP1 expression stimulated by IL29 or high glucose in (A) Raw264.7 cells or (B) primary macrophages. However, 'b $\mathrm{P}>0.05$ ' was used to describe no significant difference in TIMP1 expression between two groups with or without TLR2 (TLR4) antibodies blocking in (A) Raw 264.7 cells or in (B) primary macrophages with or without TLR2 (TLR4).

as well as TIMP1 in a concentration-independent manner (Fig. 3). Upregulated MyD88 protein expression level was detected by western blotting in high glucose group compared with low glucose group (Fig. 3A). Moreover, MyD88 protein expression was upregulated in a IL29 concentration-dependent manner. mRNA expression levels of downstream inflammation factors TNF- $\alpha$ and IL-6 were also up-regulated (Fig. 3C and D).

IL29 and high glucose activate TIMP1 release in primary macrophages. TIMP1 expression pattern in primary macrophages was similar to that in Raw264.7 cells. IL29 and high 
glucose, activated TIMP1 expression in primary macrophages in a concentration independent manner (Fig. 3E). Indeed, it was found that TIMP1 expression was significantly increased in the $100 \mathrm{ng} / \mathrm{ml}$ group compared with the 0,10 and $30 \mathrm{ng} / \mathrm{ml}$ groups.

Antibody-mediated inhibition of TLR2 and 4 inhibits TIMPI expression. Antibody-mediated inhibition of TLR2 signaling suppressed IL29-stimulated TIMP1 expression but did not affect high glucose activated TIMP1 release in the medium. In addition, high glucose-stimulated TIMP1 levels were inhibited by TLR4 antibody. However, TLR4 antibody could not suppress upregulated TIMP1 caused by IL29 (Fig. 4A).

TLR2 knockout suppresses IL29-stimulated TIMP1 expression and TLR4 knockout inhibits high glucose-activated TIMP1 level. Similar to TLR2 and 4 antibody-mediated inhibition studies, IL29 did not increase TIMP1 expression in primary macrophages extracted from TLR $2^{-/}$mice compared with macrophages extracted from TLR $2^{+/+}$mice. In addition, increased TIMP1 expression level in high glucose medium was inhibited by TLR4 gene knockout in primary macrophages (Fig. 4B).

\section{Discussion}

Diabetes mellitus and obesity patients (1-5) are characterized by disorders of MMPs and TIMPs. Extracellular matrix (ECM) substrate of MMPs deposition is associated with adipose tissue fibrosis and local and systemic insulin sensitivity $(19,20)$. TIMPs could inhibit the activity of MMPs. The expression level of MMPs exhibit various patterns in obesity. It had been reported that increased expression levels of MMP 2,3,11,12,13,14 and 19, and decreased expression levels of MMP 7,9,16 and 24 are present in high-fat-diet-induced obese mice or genetic ob/ob mice (16). TIMP1, a kind of inhibitor of ECM degradation shared the same tendency of ECM in obesity $(19,20)$. IL29 exhibits multiple immune regulatory activities and enhances production of LPS-induced inflammatory cytokines in Raw264.7 cells, accounting for the TLR4 signaling pathway (15). However, whether IL29 induces inflammatory cytokine expression without LPS, at least, with low grade LPS in obesity remains unknown. Increased IL29 levels have previously been detected in adipose tissue of humans with obesity. This is consistent with previous research. In previous work, researchers found low grade chronic inflammation in adipose tissue of obese individuals (6).

The remolding of obese adipose tissue is associated with ECM accumulation in intercellular substance (21). SVF (stromal vascular fraction) cells contribute to ECM synthesis and degradation. Macrophages, a type of SVF cell, are inflammatory regulators in adipose tissue that may induce TIMP1 expression. In the present study, IL29 was used to stimulate TIMP1 in Raw264.7 cells and primary macrophages from mice. IL29 and high glucose increased TIMP1 level in a concentration-dependent manner in the medium of Raw264.7 cells. In addition, similar results were obtained for assays using primary macrophages from C57BL/6J mice treated with IL29 and high glucose. To investigate the mechanism underlying the observed alterations in TIMP1 expression, the present study determined expression of TLR 2 and 4 by immunostaining. Furthermore, expression levels of MyD88, TNF $\alpha$ and IL6 were investigated in the medium of Raw264.7 cells. Treatment with IL29 increased TLR2 expression, while high glucose upregulated TLR4 expression. MyD88 and downstream TNF $\alpha$ and IL6 levels were stimulated by IL29 and high glucose in a synergistic manner.

The present study investigated the roles of TLR2 and 4 in modulation of TIMP1 expression in Raw264.7 cells and primary macrophages by TLR 2 or 4 antibody-mediated inhibition or gene knockout. IL29-stimulated TIMP1 expression was inhibited by antibody-mediated inhibition of TLR2 or TLR2 gene knockout. However, TLR2 inhibition or TLR2 gene knockout did not affect high glucose-mediated TIMP1 expression. Conversely, TLR4 inhibition or knockout suppressed TIMP1 levels increased by high glucose treatment, however not by IL29-mediated stimulation.

In conclusion, the results of the present study indicate that TLR2 is involved in IL29-stimulated TIMP1 expression in Raw264.7 cells and primary macrophages. High glucose activated TIMP1 expression may by mediated by TLR4 signaling.

\section{Acknowledgements}

The present study was supported by the Scientific Foundation for Doctoral Research (grant no. 20131067) and the Natural Scientific Foundation (grant no. 201602308) from Liaoning Science and Technology Administration Bureau. Professors Zheng and Zhai in the Key Laboratory of Brain and Spinal Cord Injury in Liaoning province in the First Affiliated Hospital of Jinzhou Medical University made contributions to this study. Professor Zheng provided TLR2 and TLR4 knockout mice for this study. Professor Zhai provided the Raw264.7 cell line for this study.

\section{References}

1. Chan JC, Zhang Y and Ning G: Diabetes in China: A societal solution for a personal challenge. Lancet Diabetes Endocrinol 2: 969-979, 2014.

2. Flegal KM, Carroll MD, Ogden CL and Curtin LR: Prevalence and trends in obesity among US adults, 1999-2008. JAMA 303: 235-241, 2010.

3. Flegal KM, Kruszon-Moran D, Carroll MD, Fryar CD and Ogden CL: Trends in obesity among adults in the United States, 2005 to 2014. JAMA 315: 2284-2291, 2016.

4. Ogden CL, Carroll MD, Lawman HG, Fryar CD, Kruszon-Moran D, Kit BK and Flegal KM: Trends in obesity prevalence among Children and adolescents in the United States, 1988-1994 through 2013-2014. JAMA 315: 2292-2299, 2016.

5. Xu Y, Wang L, He J, Bi Y, Li M, Wang T, Wang L, Jiang Y, Dai M, Lu J, et al: Prevalence and control of diabetes in Chinese adults. JAMA 310: 948-959, 2013.

6. Kawasaki T and Kawai T: Toll-like receptor signaling pathways. Front Immunol 5: 461, 2014.

7. Korkmaz H, Bozdag Z, Akarsu E, Tarakcioglu M, Ulusal H and Gökalp MA: Macrophage infiltration into subcutaneous adipose tissue is associated with local levels of 11BHSD1. Exp Clin Endocrinol Diabetes 124: 474-480, 2016.

8. Nam YR, Won SB, Chung YS, Kwak CS and Kwon YH: Inhibitory effects of Doenjang, Korean traditional fermented soybean paste, on oxidative stress and inflammation in adipose tissue of mice fed a high-fat diet. Nutr Res Pract 9: 235-241, 2015.

9. Xie L, Zhang K, Rasmussen D, Wang J, Wu D, Roemmich JN, Bundy A, Johnson WT and Claycombe K: Effects of prenatal low protein and postnatal high fat diets on visceral adipose tissue macrophage phenotypes and IL-6 expression in Sprague Dawley rat offspring. PLoS One 12: e0169581, 2017. 
10. de Groen RA, Boltjes A, Hou J, Liu BS, McPhee F, Friborg J, Janssen HL and Boonstra A: IFN- $\lambda$-mediated IL-12 production in macrophages induces IFN- $\gamma$ production in human NK cells. Eur J Immunol 45: 250-259, 2015.

11. Hou W, Wang X, Ye L, Zhou L, Yang ZQ, Riedel E and Ho WZ: Lambda interferon inhibits human immunodeficiency virus type 1 infection of macrophages. J Virol 83: 3834-3842, 2009.

12. Jordan WJ, Eskdale J, Srinivas S, Pekarek V, Kelner D, Rodia M and Gallagher G: Human interferon lambda-1 (IFN-lambda1/IL-29) modulates the Th1/Th2 response. Genes Immun 8: 254-261, 2007.

13. Megjugorac NJ, Gallagher GE and Gallagher G: Modulation of human plasmacytoid DC function by IFN-lambda1 (IL-29). J Leukoc Biol 86: 1359-1363, 2009.

14. Novak AJ, Grote DM, Ziesmer SC, Rajkumar V, Doyle SE and Ansell SM: A role for IFN-lambdal in multiple myeloma B cell growth. Leukemia 22: 2240-2246, 2008.

15. Xu D, Yan S, Wang H, Gu B, Sun K, Yang X, Sun B and Wang X: IL-29 enhances LPS/TLR4-mediated inflammation in rheumatoid arthritis. Cell Physiol Biochem 37: 27-34, 2015.

16. Lin, Chun TH and Kang L: Adipose extracellular matrix remodelling in obesity and insulin resistance. Biochem Pharmacol 119: $8-16,2016$.
17. Lu Z, Li Y, Samuvel DJ, Jin J, Zhang X, Lopes-Virella MF and Huang Y: MD-2 is involved in the stimulation of matrix metalloproteinase-1 expression by interferon-gamma and high glucose in mononuclear cells-a potential role of MD-2 in Toll-like receptor 4-independent signalling. Immunology 140: 301-313, 2013.

18. Song B, Ding L, Zhang H, Chu Y, Chang Z, Yu Y, Guo D, Zhang S and Liu X: Ginsenoside Rb1 increases insulin sensitivity through suppressing 11ß-hydroxysteroid dehydrogenase type I. Am J Transl Res 9: 1049-1057, 2017.

19. Zhang H, Wang R and Song B: Deposition of collagen I in adipose tissue of obese mice was inhibited by toll like receptor 2 knockout. Chin J Endocrinol Metab 33: 408-412, 2017.

20. Hopps E and Caimi G: Matrix metalloproteinases in metabolic syndrome. Eur J Intern Med 23: 99-104, 2012.

21. Luo T, Nocon A, Fry J, Sherban A, Rui X, Jiang B, Xu XJ, Han J, Yan Y, Yang Q, et al: AMPK activation by metformin suppresses abnormal extracellular matrix remodeling in adipose tissue and ameliorates insulin resistance in obesity. Diabetes 65: 2295-2310, 2016. 